\title{
The nonhospital costs of care of patients with CF in The Netherlands: results of a questionnaire
}

\author{
M.F. Wildhagen*, J.B.G.M. Verheij"*, J.G. Verzijl*, J. Gerritsen+, W. Bakker++, H.B.M.

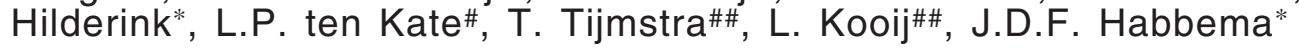

The nonhospital costs of care of patients with $C F$ in The Netherlands: results of a questionnaire. M.F. Wildhagen, J.B.G.M. Verheij, J.G. Verzijl, J. Gerritsen, W. Bakker, H.B.M. Hilderink, L.P. ten Kate, T. Tijmstra, L. Kooij, J.D.F. Habbema. @ ERS Journals Ltd 1996.

ABSTRACT: Cystic fibrosis (CF) causes a relatively high medical consumption. A large part of the treatment takes place at home. Because data regarding nonhospital care are lacking, we wished to determine the costs of care of patients with CF outside the hospital.

A questionnaire was sent to 73 patients with CF from two Dutch hospitals (response rate $64 \%, 14$ children and 33 adults). Average consumption and average costs per patient per year were calculated for children and adults for six categories: nonhospital medical care; domestic help; diet; travelling because of $\mathrm{CF}$; medication; and devices and special facilities at home, work or school.

The average nonhospital costs of care amounted to $£ 4,641$ per child per year (range $£ 712-13,269$ ) and $£ 10,242$ per adult (range $£ 1,653-26,571$ ). Nonhospital medical care for children and adults accounted for, respectively, 8 and $5 \%$ of these costs, domestic help for 15 and $9 \%$, diet for 10 and $7 \%$, travelling because of $\mathrm{CF}$ for 4 and $8 \%$, medication for 63 and $67 \%$, and devices and special facilities at home, work or school for 1 and $4 \%$.

Nonhospital costs of care of cystic fibrosis are very high and amount to $50 \%$ of the total (medical and nonmedical) lifetime costs of cystic fibrosis.

Eur Respir J., 1996, 9, 2215-2219.
*Dept of Public Health, Erasmus University, Rotterdam, The Netherlands. **Dept of Medical Genetics, University of Groningen, The Netherlands. +Beatrix Children's Clinic, University Hospital Groningen, The Netherlands. ${ }^{++}$Leyenburg Hospital, Dept of Pulmonology, Adult CF Centre, The Hague, The Netherlands. \#Dept of Human Genetics, Free University Amsterdam, The Netherlands. \#\#) Dept of Health Sciences, Northern Centre for Health Care Research, University of Groningen, The Netherlands.

Correspondence: M.F. Wildhagen, Dept of Public Health, Faculty of Medicine, Erasmus University Rotterdam, PO Box 1738, 3000 DR Rotterdam, The Netherlands

Keywords: Costs of care, cystic fibrosis, home care, The Netherlands

Received: October 261995

Accepted after revision July 51996

This study was made possible by a grant from the Praeventiefonds, The Netherlands.
Cystic fibrosis (CF) is the most frequent serious autosomal recessive disease in Caucasian populations. Characteristics of $\mathrm{CF}$ are chronic bronchopulmonary infections, pancreatic insufficiency, disturbances of the digestive tract, and high sweat-sodium concentration. The birth prevalence of CF in The Netherlands is 1 in 3,600 [1]. This means that in The Netherlands each year approximately 50 children are born with CF. The total number of patients in The Netherlands is about 1,000.

The disease has a great impact on the length and quality of life and consumes a relatively high amount of medical care. Treatment starts from the diagnosis and continues throughout life, and consists of prescribing additional calories and vitamins and fighting the respiratory infections with antibiotics and intensive physiotherapy. Care of patients with $\mathrm{CF}$ is not only intensive, but demands support from relatives, friends, colleagues etc and interferes with the normal daily life both of the patient and relatives [2].

In a previous study, the costs of medical care in the hospital were determined by reviewing the medical records of 81 patients (40 males and 41 females) of the Beatrix Children's Clinic of the University Hospital Groningen and the Leyenburg Hospital in The Hague for the years 1990 and 1991 [3]. These hospital records contain mainly information regarding medical treatment and appointments, and lack data on medical costs outside the hospital, such as physiotherapy, visits to the general practitioner and home medication, as well as the costs of nonmedical (home) care, such as domestic help, diet, travelling because of $\mathrm{CF}$ and special facilities. The results of a questionnaire survey to determine these nonhospital costs are described.

\section{Patients and methods}

We developed a questionnaire containing items about nonhospital medical care, domestic help, diet, travelling because of $\mathrm{CF}$, work/school, medication, and devices and special facilities at home, work or school. Nonhospital medical care was divided into care from general practitioner, physiotherapist and homeopath/acupuncturist. The questionnaires were supplied with a number so that a reminder could be sent if necessary; the list with numbers and names was destroyed immediately after the reminders were sent.

From the Beatrix Children's Clinic of the University Hospital Groningen, 23 children were selected in such a way that all age categories were represented. In the Leyenburg Hospital, 50 adult nonterminal patients were selected. These patients or their guardian (for children) were asked to fill in the questionnaire on a daily basis for 4 weeks in May 1993. The questionnaire was returned by 14 Groningen patients (average age $10 \mathrm{yrs}$; range 1-17 yrs) and 33 Leyenburg patients with an average age of $27 \mathrm{yrs}$ (range 16-46 yrs) (table 1). The total 
Table 1. - Age distribution of responders to questionnaire

\begin{tabular}{lc}
\hline $\begin{array}{l}\text { Age } \\
\text { yrs }\end{array}$ & $\begin{array}{c}\text { Responders } \\
n\end{array}$ \\
\hline $0-4$ & 3 \\
$5-9$ & 2 \\
$10-14$ & 6 \\
$15-19$ & 10 \\
$20-24$ & 8 \\
$25-29$ & 6 \\
$30-34$ & 6 \\
$35+$ & 5 \\
\hline Total & 46 \\
\hline
\end{tabular}

response was, therefore, $64 \%$ (47 out of 73 ). Data from one (adult) patient were not useful because this patient lived abroad. For validation purposes, six responding (parents of) patients, who had indicated they were willing to have a telephone interview, were telephoned and the questionnaire was talked through with them. It was concluded that the questionnaires were filled in carefully and meticulously. Because the questionnaire was anonymous, it could not be linked to the patient's records; therefore, it was not possible to stratify according to severity of disease.

The average consumption per patient was calculated by dividing the total units consumed of that item by the number of respondents. The average costs per patient per year were calculated by multiplying the average consumption by 13 (correction for a 4 weekly questionnaire period) and multiplying this result with the unit costs. If possible, unit costs were determined on the basis of insurer allowances. If this was not possible, data from the report "Cost calculation in health service research; guidelines for practice" [4] were used. The source of financing was not taken into account.

\section{Results}

The average consumption per item and the costs of nonhospital care per year for children and adults with $\mathrm{CF}$ are presented in tables 2 and 3, respectively. In these tables, ranges of consumption and costs are also shown, and the weighted average of the consumption and costs for an "average" patient in The Netherlands, where 36\% of the patients are adult (aged $\geq 18$ yrs) (J.M. Collée, Dutch CF registration, personal communication).

\section{General practitioner, physiotherapist and homeopath/acu- puncturist}

One child (7\%) and eight adults (25\%) consulted their general practitioner (GP) in the 4 weeks under study for a total of one and nine consultations, respectively. It was, therefore, estimated that a CF child has on average 0.9 GP consultations per year and an adult 3.7. At a cost per consultation of $£ 10.21$, this amounted to $£ 9$ per child with $\mathrm{CF}$ per year and $£ 37$ per adult.

Six children (43\%) and 14 adults $(44 \%)$ indicated that they had visited a physiotherapist for 4.7 and 5.9 times per respondent per 4 weeks, respectively. This means that a child with $\mathrm{CF}$ visited a physiotherapist on average 26 times a year and an adult 34 times. The corresponding costs were $£ 335$ per year for children and $£ 435$ for adults, at a cost of $£ 12.89$ per consultation.

Five persons (one child and four adults) consulted a homeopath or acupuncturist, of whom one patient had four consultations and one had two. Average consultations per year were 0.9 for children and 3.3 for adults. At a cost of $£ 21.23$ per consultation, this means that consultations with a homeopath or acupuncturist cost $£ 20$ per child per year and $£ 69$ per adult.

Table 2. - Consumption of nonhospital care per year for patients with CF

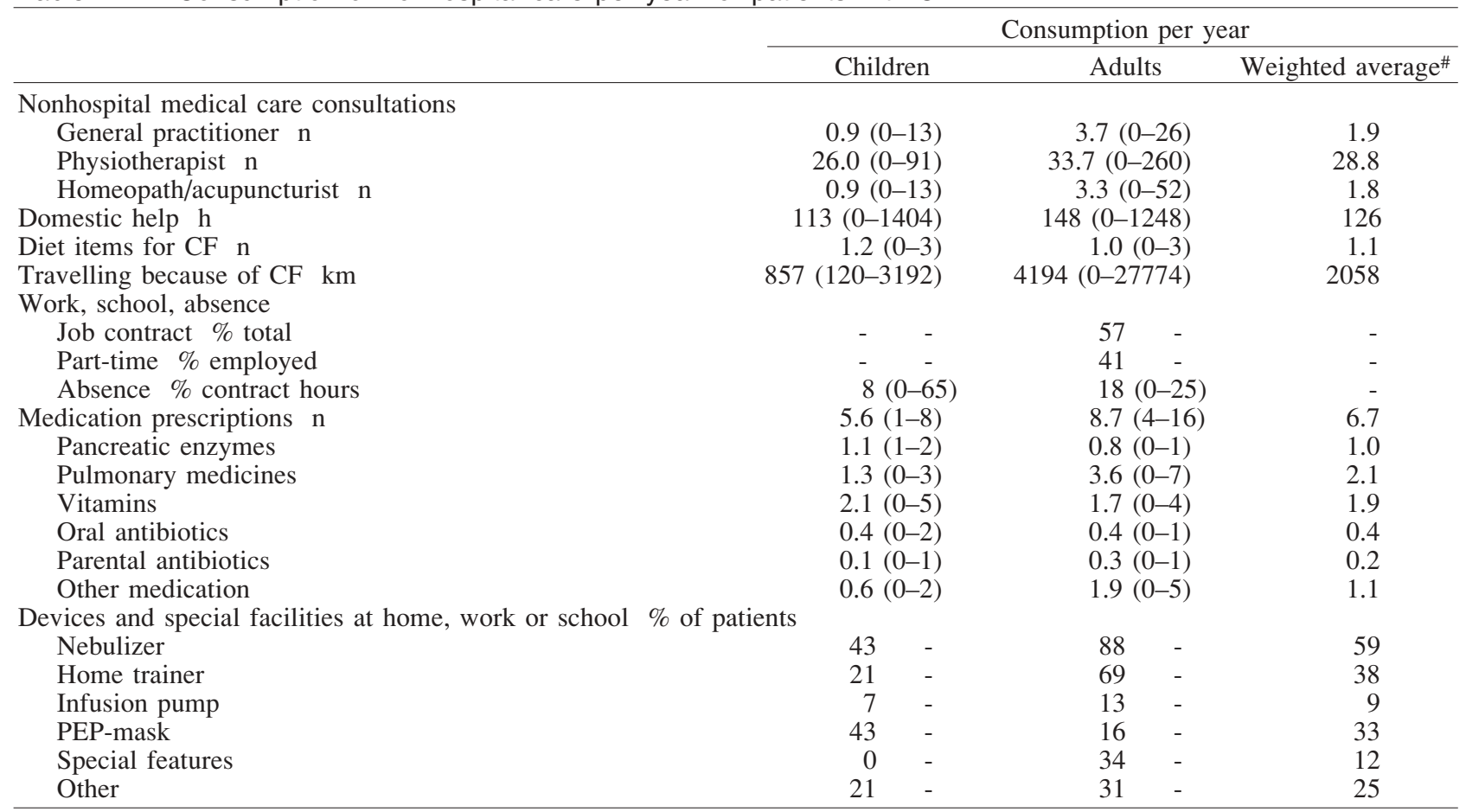

Values are presented as average, and range in parenthesis. \#: per year for a Dutch CF patient. CF: cystic fibrosis; PEP: positive expiratory pressure. 
Table. 3. - Nonhospital costs of care in $£$ per year for a patient with cystic fibrosis (CF)

\begin{tabular}{|c|c|c|c|}
\hline & \multicolumn{3}{|c|}{ Costs per year $£$} \\
\hline & Children & Adults & $\begin{array}{l}\text { Weighted } \\
\text { average\# }\end{array}$ \\
\hline Nonhospital medical care & $364(0-1173)$ & $541(0-3617)$ & 428 \\
\hline Domestic help & $687(0-8517)$ & $897(0-7571)$ & 763 \\
\hline Diet for $\mathrm{CF}$ & $447(0-1693)$ & $724(0-2632)$ & 547 \\
\hline Travelling because of $\mathrm{CF}$ & $164(23-610)$ & $801(0-5307)$ & 393 \\
\hline Pancreatic enzymes & $1434(292-3141)$ & $1239(0-2925)$ & 1364 \\
\hline Pulmonary medicines & $326(0-1843)$ & $2035(0-9558)$ & 941 \\
\hline Vitamins & $114(0-311)$ & $187(0-873)$ & 140 \\
\hline Oral antibiotics & $827(0-8900)$ & $1767(0-4476)$ & 1165 \\
\hline Parental antibiotics & $145(0-1042)$ & $888(0-17253)$ & 413 \\
\hline Other medication & $66(0-291)$ & $787(0-4785)$ & 326 \\
\hline Devices and special facilities at home, work or school & $67(0-266)$ & $375(0-2776)$ & 178 \\
\hline Total nonhospital costs of care & 4641 (712-13269) & $10242(1653-26571)$ & 6657 \\
\hline
\end{tabular}

Values are presented as average, and range in parenthesis. \#: costs per year for Dutch CF patients.

\section{Domestic help}

Fourteen adult patients $(44 \%)$ responded that they had domestic help for an average of $26 \mathrm{~h}$ during the 4 weeks. This corresponds to almost $148 \mathrm{~h} \cdot \mathrm{yr}^{-1}$ per adult patient. With standardized costs of $£ 6.07$ per hour, this amounts to $£ 897$ per adult patient per year.

Caring for a child with CF costs the parents/guardians a lot of extra time in comparison with a child without $\mathrm{CF}$; these costs were only taken into account if the parents had some domestic help. Three parents of children with $\mathrm{CF}(21 \%)$ received help from a caretaker or relative for $41 \mathrm{~h}$ on average during the 4 weeks which corresponds to $113 \mathrm{~h}$ domestic help and $£ 687$ per child per year.

\section{Diet for $C F$}

Diet used by patients with $\mathrm{CF}$ aims at ameliorating the physical condition of the patient. Sixty-three percent ( 29 out of 46) of all patients indicated that they used a supplemental or special diet. Most patients used calorie concentrates: Fortisip ${ }^{\circledR}$ (used by 16 patients); Polycal ${ }^{\circledR}(12)$; Nutrison ${ }^{\circledR}(5)$; Nutrilon ${ }^{\circledR}(5)$; and Meritene and Protifar (1 each). Furthermore, snacks such as Evergreen ${ }^{\circledR}$, Mars ${ }^{\circledR}$ and Nuts ${ }^{\circledR}$ were used by three patients, and other products such as shakes (two patients) and camomile tea, celery soup and cream (one patient each). Average costs for a CF-specific diet amounted to $£ 447$ per year for children and $£ 724$ for adults.

\section{Travelling because of $C F$}

Almost all respondents, 45 persons (98\%) answered that during the 4 weeks they had travelled once or more because of CF, children on average $66 \mathrm{~km}$ and adults $333 \mathrm{~km}$ in the 4 weeks. This corresponded to 857 and $4,194 \mathrm{~km}$ per patient per year; costing £164 and £801 per year at $£ 0.19$ per $\mathrm{km}$.

\section{Work, school and absence}

Fifty-seven percent (17 persons) of the adult patients reported that they held a contract of employment, of which almost 50\% had a part-time job. During the 4 weeks, five persons had been absent due to CF for a total of 13 days $(104 \mathrm{~h})$, which was $18 \%$ of the total contract hours of all 17 patients who had a contract $(570$ h). As a comparison, in the general population absence due to sickness in The Netherlands in this period was $5.8 \%$ for males and $8.9 \%$ for females [5].

Three out of 18 patients (17\%) who attended school had been absent for one or more days; average absence for these three patients in the 4 weeks was 9 days. This means that a child with $\mathrm{CF}$ was on average absent from school for 19.5 days per year. National data concerning school absence are not known.

\section{Medication}

All patients used medication for CF (children on average 5.6 different medicines and adults 8.7). For a better overview, medication has been divided into six groups: pancreatic enzymes (14 children and 25 adults); pulmonary medicines ( 8 children and 29 adults); vitamins (11 children and 25 adults); oral antibiotics (5 children and 14 adults); parenteral antibiotics ( 2 children and 9 adults); and other medication ( 6 children and 25 adults).

The pancreatic enzymes were either pancrelipase (10 children and 23 adults) or pancreatin ( 5 children and 1 adult). Average costs per year amount to $£ 1,434$ for children and $£ 1,239$ for adults.

In the pulmonary medicines group, many different preparations were used. Salbutamol was used most frequently in this group ( 3 children and 18 adults), followed by colistin by nebulization ( 2 children and 17 adults), and acetylcysteine and ipratropium bromide (12 patients each). Other medicines were used less than 10 times. As mucolytic agent, mercaptoethanesulphonate was recorded 13 times and acetylcysteine 12 times. On average, 3.6 different prescriptions were taken by the users of pulmonary medicines (children 2.3 and adults 3.9 ). Average costs amounted to $£ 326$ per year for children and $£ 2,035$ for adults.

The vitamins A, B, C, D, E and $\mathrm{K}$ and multivitamins were prescribed in different combinations. The average costs per patient per year amounted to $£ 114$ for children and $£ 187$ for adults. 
In the oral antibiotics group, eight different medicines were indicated in the questionnaire. Of these, co-trimoxazole was used most frequently ( 1 child and 6 adults). Two patients indicated that they used co-trimoxazole for a fixed period of 8 months and 3 weeks, respectively. The other patients did not indicate a fixed period of use. Ciproxin therapy was used by three patients for an average of 3 weeks per patient. Average costs for the oral antibiotics group were $£ 827$ per year for children and $£ 1,767$ for adults.

In the parenteral antibiotics group, three different medicines were noted: flucloxacillin ( 2 children and 7 adults), ceftazidime and tobramycin (both used by one adult). Flucloxacillin therapy was used by two patients for 3 and 13 weeks, respectively. Ceftazidime was used as a cure for 3 weeks. Average costs for the group parenteral antibiotics were $£ 145$ per year for children and $£ 888$ for adults.

In the "other medication" group, 31 users recorded 70 medicines; the most widely-used were insulin ( 7 adults, no children), ranitidine and ursodeoxycholic acid (both 5 adults, no children). Four patients used two homeopathic medicines on average. Average costs per patient per year amounted to $£ 66$ for children and $£ 787$ for adults.

\section{Devices and special facilities at home, work or school}

Three quarters of the respondents (6 children and 28 adults) used a nebulizer with (average) cost price of $£ 475$. Using an (annuity) amortization scheme of $10 \mathrm{yrs}$ and an interest rate of $5 \%$, this amounted to $£ 26$ per year for children and $£ 94$ for adults. Almost a quarter of the respondents ( 6 children and 5 adults) used a positive expiratory pressure (PEP)-mask (cost price $£ 73$ ), average $£ 9$ per child per year and $£ 3$ per adult. For ameliorating or retaining the physical condition, 22 adult respondents and 3 children used a home trainer and/or rowing device (average cost price $£ 235$ ) or $£ 3$ per child per year and $£ 22$ per adult, with an amortization scheme of 10 yrs. Four adults used an infusion pump at home (3 Cadd-plus and 1 Cadd-1), and one child used a Flocare device. Average costs for infusion pumps were $£ 7$ per child per year and $£ 116$ per adult. Other devices were extra diapers (1), vibracan (1), ambulant oxygen device (2), lung volume gauge (2) and air cleaner (1): average costs per year $£ 21$ for children and $£ 54$ for adults. Five persons ( 4 children and 1 adult) did not use any device.

For eight (adult) respondents, a special facility at home or at work had been made, e.g. a home trainer, shower and oxygen at work, a personal (handicapped) parking place and a shower-seat at home. The costs for an average adult patient with $\mathrm{CF}$ were $£ 87$ per year.

Average costs for devices and special facilities at home, work or school consequently amounted to $£ 67$ per year for children and $£ 375$ per year for adult patients.

\section{Discussion}

The disease CF has a great impact on the daily life of the patient and family. In this study, it was found that the majority of patients had a special diet and $74 \%$ sprayed with a nebulizer one or more times a day for about $30 \mathrm{~min}$. Almost all patients had medical care outside the hospital during the survey period: whereas $43 \%$ had visited a physiotherapist, it can be assumed that the other 26 patients performed exercises themselves. Total nonhospital costs of CF care in The Netherlands amounted to $£ 4,641$ per year for children and $£ 10,242$ for adults. However, the costs of nonhospital care of children should be considered with caution because data from only 14 children were collected.

This study is obviously most relevant to the Dutch situation, but a significant part of it could be used to assess costs for other (European) countries as well. Possible differences might be the rather low number of consultations with a general practitioner $(0.9$ per year for children and 3.3 for adults) and (reimbursed) visits to a physiotherapist (26 times per year for children and 34 times for adults).

Caring for a family member or friend with $\mathrm{CF}$ takes much time and energy. For example, almost half of the adult patients had domestic help. These "direct costs" were taken into account in this analysis. On the other hand, caring for a child with $\mathrm{CF}$ takes more time for parents/guardians than caring for a child without CF. The use of these so-called "indirect costs", mainly production losses, is disputed among economists. Therefore, these costs of caring and of absence from work were not included in the calculation.

$\mathrm{CF}$ is a disease for which tremendous progress is being made in the field of medical care. Some developments have already become reality since the time of our data collection, such as recombinant human deoxyribonuclease (DNase) I to decrease the viscosity of purulent airway secretions, and the increasing use of (heart-) lung transplantations. Other developments have the possibility of progressing to the point of widespread clinical use, such as gene therapy [6-9]. This progress in treatment will obviously have an impact on the length and quality of a patient's life, and will probably have a major influence on the use and type of home care and, thus, on the costs of nonhospital care. The results of the present analysis should, therefore, be updated regularly.

The results of this analysis have been used in the calculation of the total costs of the disease cystic fibrosis [10]. For this reason, the medical consumption per age category was determined and the nonhospital costs added. These totals were discounted with a $5 \%$ interest rate and were corrected for the survival curve (median age $27 \mathrm{yrs}$ ) of the Dutch CF-registration [11], which comprises 3,302 observed patient-years. In this way, the so-called lifetime costs of CF were determined at $£ 164,365$, of which $£ 82,205(=50 \%)$ were costs made outside the hospital. Considering the cost-effectiveness of, for example, continuous intravenous home treatment of airway infections [12], the shift from hospital to extramural care could eventually lead to lower costs of the disease. On the other hand, an increase in the number of lung transplantations is expected to occur, so that the future total costs of care is difficult to predict.

The lifetime costs of CF have been used to prospectively evaluate costs of screening for carriers of the $\mathrm{CF}$ gene [13]. A choice for or against genetic screening on the basis of economic motives is completely rejected by the authors. Recently, a committee of the Dutch Health 
Council has formulated a set of reasonable criteria for genetic screening programmes [14]. Cost aspects can play a role in evaluating whether or not an otherwise desirable screening programme can be organized, or that costs of screening can be prohibitive. The results of our costs study [13] indicate that costs are probably not prohibitive for cystic fibrosis screening.

\section{References}

1. ten Kate LP. Cystic fibrosis in The Netherlands. Int $J$ Epidemiol 1977; 6(1): 23-34

2. Gerritsen J, van der Laag H, Sinnema G, Knol K. Guidance of children and adolescents with cystic fibrosis. Lung 1990; 168: 474-480.

3. Verzijl JG, Hilderink HBM, Verheij JBGM, Kooij L, Habbema JDF, ten Kate LP. Costs of cystic fibrosis (CF) and costs of screening for $\mathrm{CF}$ carriers in The Netherlands. In: Escobar H, Baquero F, Suárez L, eds. Clinical Ecology of Cystic Fibrosis. Madrid, Exerpta Medica, Elsevier Science Publishers B.V., 1993; pp. 313-318.

4. Rutten FFH, van Ineveld BM, van Ommen R, van Hout BA, Huijsman R. Kostenberekening bij gezondheidszorgonderzoek; richtlijnen voor de praktijk. Instituut voor Medische Technology Assessment, 1993.

5. Statistics Netherlands. Monthly bulletin of health statistics. Statistics Netherlands, 1994; Vol. 13, No. 94/5.
6. Tamm M, Higenbottam T. Heart-lung and lung transplantation for cystic fibrosis: world experience. Semin Respir Crit Care Med 1994; 15: 414-425.

7. Mylett J, Johnson K, Knowles M. Alternate therapies for cystic fibrosis. Semin Respir Crit Care Med 1994; 15: 426-433.

8. Wilson JM. Cystic fibrosis: strategies for gene therapy. Semin Respir Crit Care Med 1994; 15: 439-445.

9. Rosenstein BJ. Cystic fibrosis in the year 2000. Semin Respir Crit Care Med 1994; 15: 446-451.

10. Wildhagen MF, Verheij JBGM, Hilderink HBM, et al. Costs of care of patients with cystic fibrosis in The Netherlands in 1990-1991. Thorax 1996; 51(3): 298-301.

11. ten Kate LP, Halley DJJ. Genetische aspecten van "cystic fibrosis". Tijdschr Huisartsgeneeskd 1995; 12: 195198.

12. Bakker W, Vinks AATMM, Mouton JW, de Jonge P, Verzijl JG, Heijerman HGM. Continue intraveneuze thuisbehandeling van luchtweginfecties met ceftazidim via een draagbare pomp bij patiënten met cystische fibrose; een multicentrisch onderzoek. Ned Tijdschr Geneeskd 1993; 137: 2486-2491.

13. Wildhagen MF, Hilderink HBM, Verzijl JG, et al. Costs, effects and savings of screening for CF gene carriers. (Submitted 1996).

14. Health Council of the Netherlands. Committee on Genetic Screening. Genetic screening. The Hague, Health Council, 1994; No. 1994/22E. 